1. Department of Surgery, Shalamar Medical \& Dental College, Lahore, Pakistan

2. Department of Surgery,

Shalamar Medical \& Dental College Lahore, Pakistan

3. Department of Surgery,

Shalamar Medical \& Dental College Lahore, Pakistan

4. Department of Surgery,

Shalamar Medical \& Dental College,

Lahore, Pakistan

Correspondence Address:

Dr. Talat Waseem,

Assistant Prof. of Surgery

Division of Surgical Oncology and

Endocrine Surgery

Shalamar Medical \&

Dental College, Lahore.

twaseem@gmail.com

Article received on:

16/05/2016

Accepted for publication:

20/07/2016

Received after proof reading:

10/09/2016

\section{A RARE SALIVARY DUCT PAROTID TUMOR; MANAGEMENT BY TOTAL CONSERVATIVE PAROTIDECTOMY AND FREE FLAP TRANSFER \\ twaseem@gmail.com}

\begin{abstract}
Dr. Muhammad Hasham Ashraf', Dr. Asad Azim², Dr. Talat Waseem ${ }^{3}$, Dr. Khawaja M. Azim ${ }^{4}$
\end{abstract}
ABSTRACT... Salivary Duct Carcinoma is a rare but highly aggressive tumor of the parotid gland. This tumor histologically shares the features of invasive duct cell carcinoma of breast. Here we present a case of such an advanced T4aN2M0 tumor involving overlying skin and level I and II lymph nodes which was managed by radical conservative parotidectomy followed by free radial forearm flap. Patient postoperatively received chemo radiation and is recurrence free over a period of two years. We also give a brief account of literature review regarding Salivary Duct Carcinoma and its management.

Key words: $\quad$ Salivary Duct Carcinoma; Parotidectomy; Radial Forearm Flap;

Article Citation: Ashraf MH, Azim A, Waseem T, Azim KM. A rare salivary duct parotid tumor; management by total conservative parotidectomy and free flap transfer. Professional Med J 2016;23(9):1163-1166. DOI: 10.17957/TPMJ/16.3447

\section{INTRODUCTION}

Salivary duct carcinoma is a rare tumor accounting for $1-3 \%$ of all malignant salivary gland tumors. ${ }^{1,2}$ Initially, a group of malignant salivary gland tumors characterized by ductal formations and central necrosis were first described by Kleinsasser et al. in $1968 .^{3}$ These tumors have enormous potential to invade the surrounding structures directly or through perineural and lymphatic spread. Generally the prognosis is considered poor to other less aggressive tumors of the parotid. ${ }^{1-3}$ Few such cases have been reported previously hence biologic behavior and pathological characteristics are yet to be determined.

\section{CASE REPORT}

A 50 year old patient presented with a palpable tumor of right parotid gland with involvement of overlying skin and few palpable level I and II cervical lymph nodes. On CT scan the lesion measured $4.3 \times 2.6 \times 5.8 \mathrm{~cm}$ in diameter arising from superficial lobe of the right parotid with partial involvement of deep lobe. The lesion also involved overlying skin and level II and III deep cervical lymph nodes however spared the carotid sheath and other vital structures in the vicinity. FNAC of the lesion showed malignant cells with suspicion of mucoepidermoid carcinoma of the parotid gland with radiological staging mounting to T4N2M0. Radical partial conservative parotidectomy with modified radical neck dissection was carried out. The tissue defect was filled with free radial forearm flap. Histopathology showed salivary duct cell carcinoma with free resection margins and 3 out of 45 lymph nodes had metastatic deposits. Patient had postoperative chemo radiation and is recurrence free for last two years.

\section{DISCUSSION}

Highly aggressive salivary duct carcinoma of the parotid gland is relatively uncommon tumor. About 200 cases have been reported in the English literature. ${ }^{1-4}$ These tumors exhibit great histological similarities to the invasive duct cell carcinoma of female breast that is why it has been dubbed as "salivary duct carcinoma". ${ }^{5}$ Merely $1 \%$ to $3 \%$ of all malignant salivary gland tumors fall under this category. ${ }^{1-5}$ The parotid gland is most commonly involved. Tumour has got inherent tendency to involve facial nerve and temporal bone via perineural spread. ${ }^{5}$ Gingival metastasis has also been reported. ${ }^{6}$ 

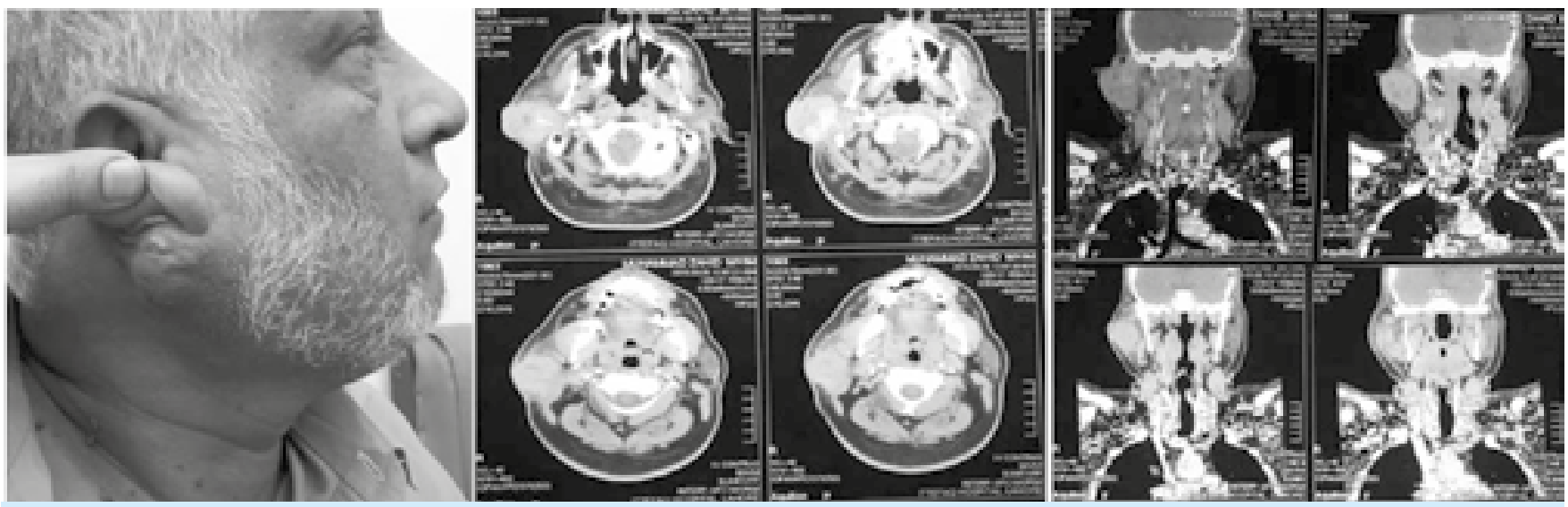

Figure-1. Tumor involving the right parotid region with involvement of the skin (left).

The CT scan shows a big tumor with involvement of the skin and few level I and II lymph nodes

(See the axial sections in middle and coronal section on right).
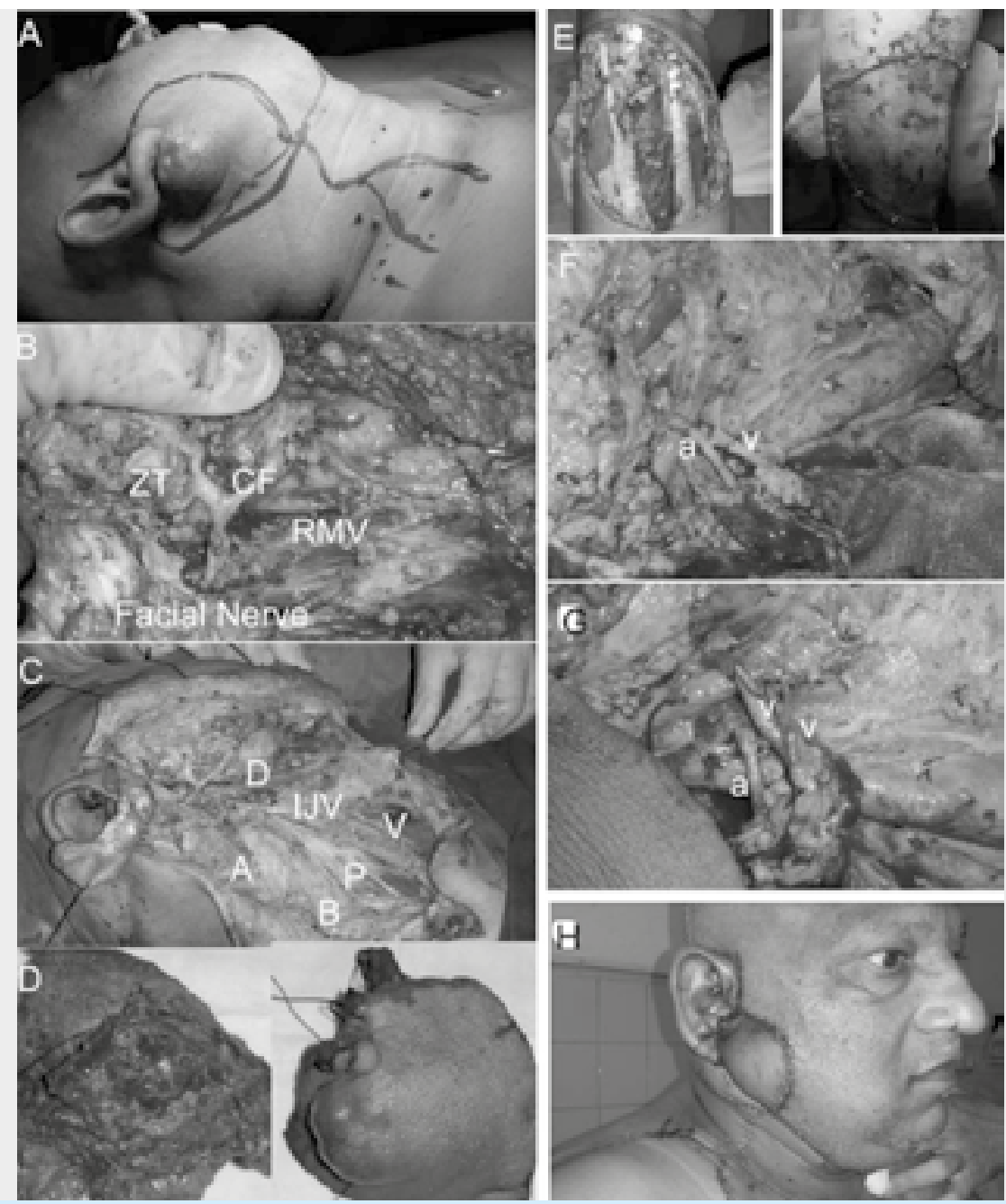

Figure-2. A, Preoperative Marking. B, Parotid bed following resection showing facial nerve, zygomaticotemporal (ZT), cervicofacial trunk (CF) and retromandibular vein (RMV). C, Bed following parotidectomy and radical neck dissection showing posterior belley of digastrics (D), internal jugular vein (IJV), vagus nerve (V), phrenic nerve (P), accessory nerve (A) and roots of brachial plexuses (B). D, anterior and posterior aspect of the resected tumor. E, Harvesting of Radial forearm flap followed by skin grafting. F-G, Flap vessel anastomosis with facial artery and vein. $\mathrm{H}$, Post reconstruction Image. 


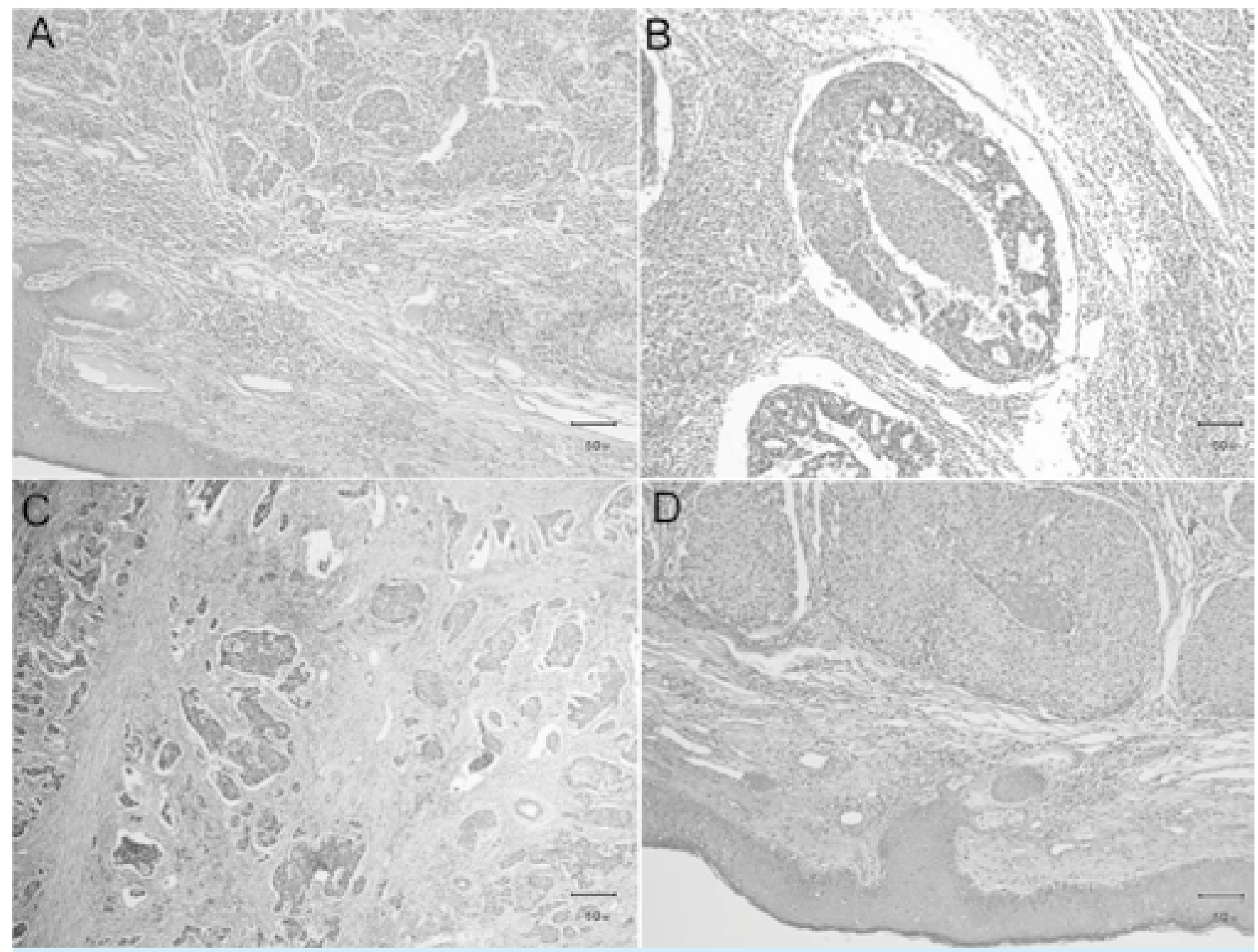

Figure-3. A, Salivary Duct Carcinoma showing the tumor arising from the salivary duct. B, histological picture assimilating invasive ductal cell carcinoma. C, high resolution Image. D, Tumor encroaching into the skin.

Other salivary glands are relatively less likely to be involved. Salivary duct carcinoma may develop ex-pleomorphic and at times denovo. This aggressive tumor involves extreme of age and involves the facial nerve in $40-60 \%$ of the cases. Nodal spread has been estimated in $35 \%$ of the cases $^{5}$ Imaging modalities in form MRI and CT scan are supportive in analyzing local and nodal extension of the tumor. ${ }^{1-6}$ Definitive diagnosis is histological. FNAC may be useful but may not be reliable like in our case; it was reported as mucoepidermoid carcinoma and later was diagnosed as a case of salivary duct cell carcinoma. Gross findings consist of a tumor of variable size with solid and cystic component. Microscopically, the most peculiar feature is the similarity to ductal carcinoma of the breast. The tumor is composed of an intraductal and invasive components. ${ }^{6-9}$ Intraductal component is cribriform, papillary, solid with comedo-like central necrosis. The infiltrative component is made of glands, cords of cells with desmoplastic reaction. Many forms have been described such as sarcomatoid salivary duct carcinoma, low-grade neoplasm, and mucinrich variant. ${ }^{8}$ Immunohistochemical findings are not useful, but a constant overexpression of keratin, HER/2 neu, CEA, and c-erd-B2 have been noted. Frequently, androgen receptors and prostate-specific antigen expression have also been reported. The cell proliferation rate (Ki-67) and the overexpression of growth factor-binding receptors like HER2/neu, p16, and p53 have been identified as important factors in the genesis of salivary gland tumors. ${ }^{8,9}$ There is no consensus 
on the therapeutic approach for such tumors but the surgeons usually agree that the resection should be aggressive. If facial paralysis is present, a radical parotidectomy is procedure of choice. In patients with involvement of the submandibular or minor salivary glands, tumor resection with wide margins of surrounding tissue is indicated to control local disease as the disease appears to be more aggressive. ${ }^{10}$ The effects of adjuvant postoperative radiotherapy remain unclear but tumor aggression dictates the use of adjuvant measures. Postoperative radiation therapy appears appropriate in case of extraparotid extension, positive resection margins and cervical lymph node metastasis. Chemotherapy is generally reserved for metastatic forms of the disease. ${ }^{11} \mathrm{~A}$ recent study reported utility of both anti-androgen therapy and chemotherapy for a patient with advanced salivary duct carcinoma. ${ }^{12}$ The tumor has bad prognosis and approximately $50 \%$ of the patients die within 5 years.

Copyright(C) 20 July, 2016.

\section{REFERENCES}

1. Cheuk W, Chan JK. "Salivary gland tumors". In: Fletcher CD, editor. Diagnostic histopathology of tumors. 2nd ed. 2000. pp. 231-311.

2. Wick MR, Ockner DM, et al. "Homologous carcinomas of the breasts, skin, and salivary glands. A histologic and immunohistochemical comparison of ductal mammary carcinoma, ductal sweat gland carcinoma, and salivary duct carcinoma." Am J Clin Pathol. 1998; 109:75-84.

3. Kleinsasser O, Klein $\mathrm{HJ}$ and Hubner G. "Salivary duct carcinoma. A group of salivary gland tumors analogous to mammary duct carcinoma." Arch Klin
Exp Ohren Nasen Kehlkopfheilkd. 1968; 192:100-5.

4. Lewis JE, Mc Kinney BC, etal. "Salivary Duct carcinoma. Clinicopathologic and immunohistochemical review of 26 cases." Cancer. 1996; 7:223-30.

5. Klijanienko J, Viehl P. "Cytologic characteristics and histomorphologic correlations of 21 salivary duct carcinomas". Diagn Cytopathol. 1997; 16:526-30.

6. Yamada S, Nabeshima A, et al. "Invasive salivary duct carcinoma ex pleomorphic adenoma of the parotid gland: a teaching case giving rise to the genuine diagnostic difficulty on an inadequate cytology specimen”. Diagn Pathol. 2012; 7:61.

7. Kim HJ, Yoo YS, et al. "Genomic aberrations in salivary duct carcinoma arising in Warthin tumor of parotid gland: DNA microarray and HER2 fluorescence in situ hybridization." Arch Pathol Lab Med. 2011; 135:1088-91.

8. Gilcrease MZ, Guzman-Paz M, et al. "Salivary duct carcinoma. Is a specific diagnosis possible by fine needle aspiration cytology?" Acta Cytol. 1998; 42:1389-96.

9. Kinnera VS, Mandyam KR, Chowhan AK, Nandyala R, Bobbidi VP and Vutukuru VR. Salivary duct carcinoma of parotid gland. J Oral Maxillofac Pathol. 2009; 13:858.

10. Khurana KK, Pitman MB, et al. "Diagnostic pitfalls of aspiration cytology of salivary duct carcinoma". Cancer Cytopathology. 1997; 81:378-8.

11. James GK, Pudek M, et al. "Salivary duct carcinoma secreting P-S antigen". Am J Clin Pathol. 1996; 106:242-7.

12. Moriki T, Ueta S, et al. "Salivary duct carcinoma: Cytologic characteristics and application of androgen receptor immunostaining for diagnosis." Cancer Cytopathology. 2001; 93:344-50.

\section{AUTHORSHIP AND CONTRIBUTION DECLARATION}

\begin{tabular}{|c|c|c|c|}
\hline Sr. \# & Author-s Full Name & Contribution to the paper & Author $=\mathbf{s}$ Signature \\
\hline 1 & Dr. M. Hasham Ashraf & $\begin{array}{l}\text { Surgical decision making, } \\
\text { surgery }\end{array}$ & \\
\hline 2 & Dr. Asad Azim & Writing of care report & \\
\hline 3 & Dr. Talat Waseem & $\begin{array}{l}\text { Writing of case report } \\
\text { surgical complication }\end{array}$ & \\
\hline 4 & Dr. Khawaja M. Azim & $\begin{array}{l}\text { Surgery / Surgical } \\
\text { complication }\end{array}$ & \\
\hline
\end{tabular}

